\title{
O ENSINO DA MATEMÁTICA E OS NÚMEROS IRRACIONAIS
}

\author{
Jailson Lima de Souza ${ }^{1}$ \\ Márcio de Freitas Santa Ana ${ }^{2}$
}

RESUMO: A matemática está presente na vida humana desde as mais remotas épocas em que o homem era um coletor onde caçava e pescava, na qual, a matemática de forma intuitiva era presente no cotidiano do homem. Analisando a matemática dentro do contexto dos princípios básicos da Educação que busca condições de igualdade para todos na escola em conjunto com a lei de diretrizes e bases da educação - LDB e com observância para uma aprendizagem mais eficaz entre professores e alunos. Este artigo busca demonstrar a presença da Matemática no cotidiano humano, desde épocas remotas na história do homem, o contexto do artigo, avalia preceitos básicos da educação, nas condições de igualdade segundo as leis diretrizes e bases na aprendizagem entre professores e alunos. O problema emerge pela falta de aprendizagem mais eficaz entre professores e alunos em uma proposta que minimize a problemática na aprendizagem, a fim de, promover uma inovação novas práticas pedagógicas para o ensino da matemática dentro dos números irracionais. Os objetivos propostos para este estudo visa de modo geral estudar as dificuldades ensino-aprendizagem da Matemática no Ensino Médio avaliada pelo ensino dos números irracionais e de maneira específica analisar as teorias e práticas da Matemática no contexto escola. Esse trabalho justifica-se com relação aos números irracionais. Sabendo da importância do 'caminhar' entre os conjuntos numéricos, visando a concepção dos números reais. Com relação aos procedimentos metodológicos, este artigo tem uma abordagem quantitativa, no modo de análise bibliográfica e experiência pessoal adquirida em sala de aula. Logo, conclui-se que este trabalho, buscará investigar o conceito e o desenvolvimento dos números irracionais.

Palavras-chave: Matemática. LDB. Aprendizagem. Números Irracionais.

\footnotetext{
I Graduado no curso licenciatura em Matemática pela Universidade Federal da Paraíba (UFPB).

Pós- graduado no ensino da Matemática pela Faculdade de Vendas Nova do Imigrante (FAVENI). E-mail: jailsomlima@bol.com.br

${ }^{2}$ Graduado no curso de Engenharia de Produção pela Universidade Salgado de Oliveira, licenciado em Física pela Faculdade Única, Pós-graduação Lato Sensu em Educação Tecnológica pelo CEFET RJ, mestrado em Ciências e Tecnologias dos Materiais, UEZO.E-mail: ciedistancia@gmail.com.
} 


\section{INTRDUÇÃO}

A matemática está presente na vida humana desde as mais remotas épocas em que o homem era um coletor onde caçava e pescava, na qual, a matemática de forma intuitiva era presente no cotidiano do homem. Ela vem sendo incluída ao longo desenvolvimento da humanidade, integrando as transformações tecnológicas e sociais que ocorrem ao longo da história da própria humanidade. A matemática ao longo do seu surgimento vem sendo desenvolvida junto às suas necessidades de sobrevivência, aumento social e adequações a ele.

Analisando a matemática dentro do contexto dos princípios básicos da Educação que busca condições de igualdade para todos na escola em conjunto com a lei de diretrizes e bases da educação - LDB e com observância para uma aprendizagem mais eficaz entre professores e alunos. Esse trabalho apresenta a ideia sobre os números irracionais, os quais foram poucos consolidados ao longo dos anos na

que a relação professores e alunos muitas vezes prejudica o processo aprendizagem demonstração na intensidade do seu ensino.

Diante deste cenário na matemática o problema emerge pela falta de aprendizagem mais eficaz entre professores e alunos em uma proposta que minimize a problemática na aprendizagem, a fim de, promover uma inovação novas práticas pedagógicas para o ensino da matemática dentro dos números irracionais.

Em relação as hipóteses que podem configurar estão a resposta no problema apresentado e se apresentam a dificuldade de confrontar o que se pretende resolver dentro dos limites dos números irracionais, tornar individual, específico e promover novas práticas pedagógicas para o ensino da matemática tendo conhecimento

Os objetivos propostos para este estudo visam de modo geral estudar as dificuldades no processo de ensino-aprendizagem da Matemática no Ensino Médio dentro dos números irracionais e de maneira especifica analisar as teorias e práticas da Matemática no contexto escolar; Identificar as principais causas das dificuldades nesse processo; Identificar os 
fatores que afetam a aprendizagem da Matemática; Avaliar a adequação das estratégias pedagógicas adotadas pelos professores de Matemática; Propor soluções viáveis para resolver o problema da aprendizagem dos alunos.

Esse trabalho justifica-se com relação aos números irracionais. Sabendo da importância do 'caminhar' entre os conjuntos numéricos, visando a concepção dos números reais, isso pode se tornar uma lacuna importante a ser preenchida, que disponibiliza o interesse de pesquisas acadêmicas sobre tal tema.

A metodologia usada se refere a uma pesquisa bibliográfica e também a minha atuação docente e considerando a experiência em sala de aula, com materiais didáticos e/ou sistemas apostilados, percebo que os números irracionais se resumiam a uma curta apresentação/introdução aos mesmos, se limitando a explicar sobre a constante PI e as raízes irracionais, praticamente definindo os mesmos apenas como o conjunto que possui essas raízes e as dízimas não periódicas.

\section{DESENVOLVIMENTO}

\section{I.I Educação}

Conforme estabelecido na Lei 9394/96 - Lei de Diretrizes e Bases da Educação Nacional (LDB):

Art. $2^{\text {O }}$ - A educação, dever da família e do Estado, inspirada nos princípios de liberdade e nos ideais de solidariedade humana, tem por finalidade o pleno desenvolvimento do educando, seu preparo para o exercício da cidadania e sua qualificação para o trabalho.

Conforme D’Ambrosio estabelece: “Através de comunicação, é possível obter um comportamento ético dos indivíduos, na execução da ação comum. A estratégia que a sociedade criou para facilitá-la é o que chamamos de educação”. (I997, p. I4I).

Educação representa fenômeno dos mais soberbos da humanidade, no sentido das estratégias colocadas teórica e praticamente às sociedades para promover as novas gerações. [...] Tem objeto próprio e eterno, dentro do desafio humano de garantir para as novas gerações oportunidades aprimoradas. 


\section{(DEMO, 2004).}

A educação precisa ser compreendida como:

Uma educação global que leve o aluno a trabalhar em harmonia e compreensão, a desenvolver padrões de comportamento positivo, criatividade, cooperação, responsabilidade e preocupação com o destino das outras pessoas. Uma educação que respeite os direitos humanos, que favoreça a compreensão mútua e a solução pacífica dos conflitos. (MORAES, 1997).

A educação possui um conceito amplo, referenciando o processo de desenvolvimento e formação humana, assim:

A educação corresponde, pois, a toda modalidade de influências e interrelações que convergem para a formação de traços de personalidade social e do caráter. (LIBÂNEO, 1994).

Segundo Saviani: "Se a educação é mediação, isto significa que ela não se justifica por si mesma, mas tem sua razão de ser nos efeitos que se prolongam para além dela e persistem mesmo após a cessação da ação pedagógica”. (1984, p. 80).

"O processo educativo é a passagem da desigualdade a igualdade". (SAVIANI, 1984, p.

\section{I)}

\subsection{O Ensino da Matemática}

No que se refere ao ensino da matemática, D’Ambrosio afirma: “o ensino da matemática ou de qualquer outra disciplina dos nossos currículos escolares, só se justifica dentro de um contexto próprio, de objetivos bem delineados dentro do quadro das prioridades nacionais.” (1997, p. 14)

[...] a detectar as dificuldades enfrentadas pelos alunos na assimilação ativa dos conteúdos e a encontrar os procedimentos para que eles próprios superem tais dificuldades e progridam no desenvolvimento intelectual. (LIBÂNEO, 1994, p. 94).

[...] a matemática é importante no ensino, mas é importante esclarecer que esta disciplina não se limita apenas à preparação de um profissional para a área de trabalho, mas assim como nas ciências humanas, também tem grande importância no desenvolvimento social dos educandos [...]. (LOPES, 2006, p. 2). 
"Para o desenvolvimento da autonomia política e intelectual é preciso um ensino da matemática que ajude o sujeito do conhecimento a decifrar a informação disponível na sociedade”. (SANTOS, p. 4).

"Ao se examinar o ensino da matemática com certa profundidade de reflexão, nota-se o quanto ela é capaz de contribuir à formação social e profissional dos alunos, proporcionandolhes desenvolvimento”. (LOPES, 2006, p. 8).

Destacamos assim elementos essenciais na evolução da Matemática e no seu ensino, o que a coloca fortemente arraigada a fatores socioculturais. Isso nos conduz a atribuir à Matemática o caráter de uma atividade inerente ao ser humano, praticada com plena espontaneidade, resultante de seu ambiente sociocultural e consequentemente determinada pela realidade material na qual o indivíduo está inserido. (D’AMBROSIO, I986, p. 36).

\subsection{As Preocupações com o Ensino da Matemática}

Os baixos índices de rendimento dos estudantes em Matemática têm fomentado o desenvolvimento de pesquisas, como os trabalhos de Paz (2011), Nunes (2013), Domingues (2013), Wilkins (2013) e De Toledo Benassi et al. (2015). Os índices são aferidos através de

avaliações de larga escala SAEB (Sistema Nacional de Avaliação Básica), a Avaliação Nacional do Rendimento Escolar (ou Prova Brasil), dentre outras e em avaliações internacionais, como o Programa Internacional de Avaliação de Alunos (Programme for International Student Assessment - PISA)

\subsection{O Movimento da Matemática Escolar no Brasil}

O foco das avaliações nacionais é aferir a qualidade, a equidade e a eficiência da educação básica brasileira, nos ditames da Prova Brasil, descrito em Brasil (2018). Por outro lado, o PISA, conforme descrito em Brasil (2015) tem por objetivo a produção de indicadores que possam contribuir para uma reflexão sobre a qualidade de educação das nações que participam, de maneira a promover a realização de políticas de melhoria para o ensino básico. 
Em Matemática, os níveis são categorizados como: nível insuficiente (o a 3); nível básico (4 a 6); nível adequado (7 a 10 ), conforme dados do MEC, divulgados em Brasil (2018). Em particular, muitas destas dificuldades podem ser atribuídas a dificuldades com a Álgebra e seu ensino e uma consideração essencial a se levar em conta é que a reflexão de Bianchini e Machado (2010), que destacam que “[...] o problema com o ensino da Álgebra reside na ênfase habitualmente dada ao simbolismo algébrico, isto é, com foco na sintaxe, mas com pouca ou nenhuma associação com a semântica (p. 354)”.

\subsection{História, Epistemologia e Ensino dos Números Irracionais}

No tocante relativo às dificuldades em Matemática, o tema dos números irracionais se situa como uma parte da matemática de difícil entendimento, desde a formação do professor até o entendimento do aluno na educação básica, como apontado nos trabalhos de Igliori e Silva (1998), Dias (2002), Rezende (2003) e Silva e Penteado (2009).

Historicamente, segundo Caraça (1970), as ações de medir e contar foram fatores importantes e cruciais para a formação dos conhecimentos envolvendo os números. $\mathrm{O}$ desenvolvimento dos povos antigos (com destaque aos povos que viviam no Egito Antigo), em especial nas áreas de agricultura e comércio, incentivaram o desenvolvimento de cálculos e a utilização de símbolos para representar os números.

Os povos egípcios e babilônicos utilizavam a matemática em aplicações práticas, pois faziam a conexão entre o uso de técnicas matemáticas às suas necessidades diárias, sem considerar algum tipo de estrutura científica. Segundo Jesus, Oliveira, (2018), esses povos já tinham conhecimento que o comprimento da circunferência/perímetro 24 do círculo poderia ser calculado através da multiplicação entre o seu diâmetro por 3. Ainda segundo os referidos autores, apesar da percepção de uma relação entre o diâmetro e o comprimento da circunferência, as ideias em torno do conceito de irracionalidade deste número seriam estabelecidas anos depois, na matemática grega. 
A matemática grega, ao contrário dos povos supracitados, se preocupava mais com processos formais e científicos do que o caráter prático. Conforme Boyer (1974), a história da matemática grega inicia de modo formal com Tales de Mileto e tem continuidade com Pitágoras de Samos. O referido autor ainda destaca que Pitágoras era considerado um profeta e fundou uma sociedade secreta com bases sólidas com relação a matemática e a filosofia.

De acordo com Mendes (2012), Pitágoras viveu por volta entre os anos de 569 e 475 (a.C.) e, desde sua primeira infância, se revelou como um prodígio. Ainda segundo o referido autor, Pitágoras teve grandes mestres, viajou muitos anos, teve contato com outros povos (como os egípcios e os babilônicos) que utilizavam a matemática de uma maneira prática e entendeu que os números eram mais do que instrumentos utilizados o processo de contagem e existiam mesmo desconectados a esse processo, Além disso,

[...] Pitágoras fez importantes descobertas para a Matemática, a Astronomia e a Música. A "teoria dos números" foi a base da escola pitagórica; acreditava-se que os números eram a essência do universo. Nesse contexto, os números tinham essência divina, devido às relações existentes entre os números e os fenômenos naturais. O encantamento desse filósofo o fez assumir como lema "Tudo é número", que perpassou por toda escola pitagórica. (MENDES, 2012, p. 42).

\section{I.4.2 O Conceito dos Números Irracionais}

O conceito dos números irracionais, segundo Pommer (2012), se consolidou há pouco mais de Ioo anos no campo do saber matemático, mas não ocorreu no campo do ensino básico da Matemática, mesmo com documentos oficiais e/ou referenciais curriculares evidenciando a necessidade do ensino de números irracionais.

A abordagem dos números irracionais em sala de aula na educação básica, segundo Pommer (2012), se torna um processo difícil, devido ao conteúdo representar uma 
ideia matemática sofisticada, não trivial e pouco intuitiva. Contudo, o referido autor destaca que, considerando a complexidade do conteúdo matemático em questão e sua importância para a concepção do conjunto dos números reais, deve-se buscar recursos e meios para conceber uma aprendizagem significativa e com menos dificuldades aos alunos

Em particular, muitas destas dificuldades podem ser atribuídas a dificuldades com a Álgebra e seu ensino e uma consideração essencial a se levar em conta é que a reflexão de Bianchini e Machado (2010), que destacam que “[...] o problema com o ensino da Álgebra reside na ênfase habitualmente dada ao simbolismo algébrico, isto é, com foco na sintaxe, mas com pouca ou nenhuma associação com a semântica (p. 354)”.

Neste contexto, o tema dos números irracionais se enquadra nesta preocupação apontada pelas supramencionadas autoras. Complementando este quadro, a pesquisa de Pommer, 2012 destaca que a denominada etapa de transição dos números racionais para os números reais deve levar em conta uma apresentação cuidadosa dos números irracionais.

Os números irracionais são parte de um sistema e ficam incompletos sem a conceituação dos números reais. Renegar os números irracionais é suficiente para derrubar todo o sistema. Isto é o que acontece hoje em dia (POMMER, 2012, p. 23)

Nesse sentido, se torna necessária a compreensão de que devemos evitar que os números irracionais sejam compreendidos como "[...] um amontoado de regras de operar com radicais, as quais acabam sendo vistas pelos estudantes como um conhecimento pouco significativo, pouco desafiador e desligado dos demais temas [...]” (BRITO, MIGUEL, CARVALHO, 2009, p. 270).

\section{CONCLUSÃO}

Neste artigo se pode constatar da experiência em sala de aula e por pesquisa bibliográfica que processo de ensino e aprendizagem acerca dos números irracionais, é necessário um aprofundamento, de modo a, perceber a construção dos números reais, bem como a construção dos campos numéricos relativos ao entendimento dos números irracionais sendo tratado com maior relevância neste trabalho 
Evidente que sua complexidade na unidade, na prática, escolar os números irracionais dentro do contexto de reais devem ser desenvolvidos desde o ensino fundamental de forma que não seja tanto axiomático em detrimento de modelo construtivo, sendo primordial que este tema seja Tratado de forma aprofundada em seus aspectos conceituam na formação do professor de matemática de modo a tornar o aprendizado mais relevante para os alunos

Por fim se destaca a Importância deste trabalho voltado na representação e na participação dos professores de matemática no contexto da compreensão de um método em que a aprendizagem possa proporcionar uma etapa produtiva e significativo no desenvolvimento dos alunos.

\section{REFERENCIAS}

BIANCHINI, B. L.; MACHADO, S. D. A. A Dialética entre Pensamento e Simbolismo Algébricos. Educação Matemática Pesquisa, v. 12, n. 2, p. 354-368, 2010.

BOYER, C. B. História da matemática; tradução: Elza F. Gomide. São Paulo, Edgard Blucher, I974.

BRASIL: Lei 9.394 - Lei de Diretrizes e Bases da Educação Nacional, 1996.

BRASIL. Base Nacional Curricular Comum. Brasília: SET/MEC, 2016.

- Programa Internacional de Avaliação de Estudantes (Pisa). 2015. Brasília: Instituto Nacional de Estudos e Pesquisas Educacionais Anísio Teixeira.

. Prova Brasil: Apresentação. Brasília: MEC, 2018.

BRITO, A. de J.; MIGUEL, A.; CARVAlHO, D. L. História da Matemática em atividades didáticas. São Paulo: Livraria de Física, 2009.

CARAÇA, B. J. Conceitos Fundamentais da Matemática. 5. ed. Portugal: Lisboa, 1970.

D’AMBROSIO, Ubiratan. Transdisciplinaridade. São Paulo: Palas Athena, 1997.

DE TOLEDO BENASSI, Marcos et al. Ensino de Matemática no Ensino Fundamental II: as avaliações padronizadas e os resultados brasileiros. Ensino da Matemática em Debate (ISSN 2358-4122), [S.1.], v. 2, n. I, jun. 2015.

DEMO, Pedro. Sociologia da educação. Brasília: Plano Editora, 2004. 
DIAS, M. .da S. Reta real: conceito imagem e conceito definição. 2002. 107 f. Dissertação (Mestrado em Educação Matemática). Pontifícia Universidade Católica, São Paulo.

DOMINGUES, M. R. S. As implicações da Prova Brasil na política de formação dos professores da SEMEC entre os anos de 2005 a 2011. 2013. I44 f. Dissertação (Mestrado). Universidade Federal do Pará, Instituto de Ciências da Educação, Belém.

JESUS, B. C. D.; OLIVEIRA, V. C. A. Sobre números irracionais e possibilidades para seu ensino. Instrumento. Juiz de Fora, v. 20, n. 2, jul./dez. 2018.

IGLIORI, S. B. C.; SILVA, B. A. Conhecimentos das concepções prévias de estudantes sobre números reais: um suporte para melhoria do ensino-aprendizagem. In: Anais... REUNIÃO ANUAL DA ANPED, 21, 1998, Caxambu, p. I-20.

INAYO, M. C. S. O desafio do conhecimento: pesquisa qualitativa em saúde. $4^{\underline{a}}$ ed. São Paulo: Abrasco, i996M.

LIBÂNIO, José Carlos. Didática. Ed. 19. São Paulo: Cortez, i994.

LOPES, Washington Lauriano. Filosofia da educação matemática reflexão e pesquisa sobre a importância do ensino de matemática. Disponível em 32 http://www.unimesp.edu.br/arquivos/mat/tcco6/Artigo_Washington_Lauriano_Lopes. pdf. Acesso em I4 ago. 2008

LUCKESI, C. C. Avaliação da aprendizagem escolar. São Paulo, Cortez, 200 .

MINICUCCI, Agostinho. Dinâmica de Grupo. Manual de técnicas. São Paulo: Atlas, 1997.

MENDES, S. C. da C. Práticas pedagógicas para o ensino dos números irracionais. 2012. IIzf. Dissertação (Mestrado em Educação Matemática), Universidade Severino Sombra, Vassouras.

MORAES, Maria Cândida. O paradigma educacional emergente. Campinas:Papirus, 1997.

NUNES, S. M. L. A proficiência matemática dos alunos brasileiros no PISA 2003: uma análise dos itens de incerteza. 2013. 218 f. Tese (Doutorado em Educação). Universidade Federal de Minas Gerais, Belo Horizonte.

NETO, Ernesto Rosa. Didática da matemática. Iı ed. São Paulo: Ática, 200 I.

PAIS, L. C. Transposição Didática. In: MACHADO, S. D. A. et al (Org.). Educação Matemática: Uma (nova) introdução. 3. ed. São Paulo: Educ, 2oı6. p. ıı-48.

POMMER, W. M. A construção de significados dos Números Irracionais no ensino básico: Uma proposta de abordagem envolvendo os eixos constituintes dos Números Reais. 


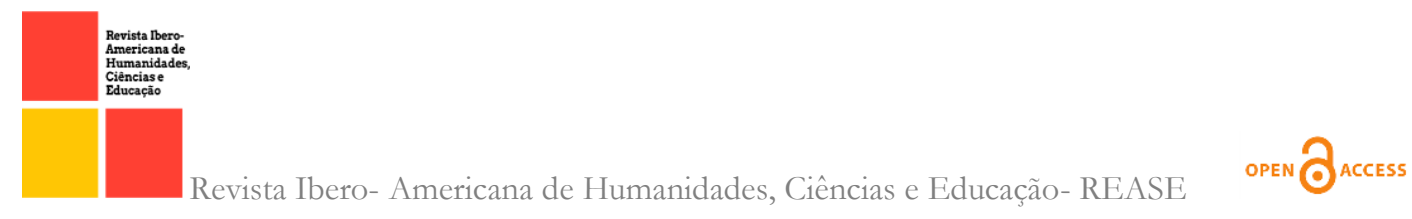

2012. 235 f. Tese (Doutorado). Faculdade de Educação da Universidade de São Paulo, São Paulo.

REZENDE, W. M. O ensino de Cálculo: dificuldades de natureza epistemológica. 2003. 468 f. Tese (Doutorado em Ensino de Ciências e Matemática) - Universidade de São Paulo, São Paulo, 2003.

SAVIANI, Dermeval. Escola e democracia. São Paulo: Cortez, 1984.

SILVA, B. A. da; PENTEADO, C. B. Fundamentos dos números reais: concepções de professores e viabilidade de início do estudo da densidade no Ensino Médio. Educação Matemática em Pesquisa, São Paulo, v. II, n. 2, p. 351-37ı, 2009.

WILKINS, S.L. Princípios e propostas sobre o conhecimento matemático nas avaliações externas. 2013. Dissertação (Mestrado em Educação) - Faculdade de Filosofia, Ciências e Letras de Ribeirão Preto, Universidade de São Paulo, Ribeirão Preto, 2013. 